\title{
A mitigation of channel crosstalk effect in dispersion shifted fiber based on durability of modulation technique
}

\author{
Ali Shaban', Murad Obaid Abed ${ }^{2}$, Ehab Abdul Razzaq Hussein ${ }^{3}$, H. J. Abd ${ }^{4}$ \\ ${ }^{1}$ Department of Biomedical Engineering, University of Babylon, Iraq \\ 2,3,4 Department of Electrical Engineering, University of Babylon, Iraq
}

\begin{tabular}{|c|c|}
\hline Article Info & ABSTRACT \\
\hline Article history: & In fiber optics the Four Wave Mixing (FWM) has the harmful effect of \\
\hline Received Apr 3, 2019 & Multiplexing (WDM) and reduce the transmission aptness. This work preset \\
\hline Revised Sep 11, 2019 & the durability of the different modulation format was tested to FWM by using \\
\hline Accepted Sep 27, 2019 & $\begin{array}{l}\text { Dispersion Shifted Fiber (DSF). Moreover, the performance of the proposed } \\
\text { system is surveyed by changing the fiber length and applying an information }\end{array}$ \\
\hline Keywords: & $\begin{array}{l}\text { rate of } 200 \mathrm{~Gb} / \mathrm{s} \text {. The experimental results show that the FWM capacity has } \\
\text { decreased significantly by more than } 14 \mathrm{~dB} \text { when applying Return to Zero }\end{array}$ \\
\hline FWM crosstalk & (RZ) modulation form. In addition, in terms of the propsed system \\
\hline MDRZ & $\begin{array}{l}\text { performance in the first channel and with } 700 \mathrm{~km} \text { distance, it was observed } \\
\text { that the lower Bit Error Rate (BER) in the normal RZ modulation is equal to }\end{array}$ \\
\hline Modulation formats & $1.3 \times 10^{-13}$. As well as it is noticeable when applied the Non Return to Zero \\
\hline & (NRZ), the Modified Duobinary Return to Zero (MDRZ) and Gaussian \\
\hline WDM system & $\begin{array}{l}\text { modulation, the system performance will be quickly changed and getting } \\
\text { worse, where the BERs increased to } 1.3 \times 10^{-4}, 1.3 \times 10^{-6} \text { and } 1.3 \times 10^{-2} \\
\text { consecutively at same channel and for the same parameters. }\end{array}$ \\
\hline
\end{tabular}

Copyright $\odot 2020$ Institute of Advanced Engineering and Science. All rights reserved.

\section{Corresponding Author:}

Ehab AbdulRazzaq Hussein,

Department of Electrical Engineering,

University of Babylon,

Hillah-Najaf Road, Babylon, Iraq.

Email: dr.ehab@itnet.uobabylon.edu.iq

\section{INTRODUCTION}

With the fast development of telecommunication services, the needing for large capacity transmission has been increased. Therefore, dense wavelength-division multiplexing systems may be a suitable approach to cover these demands [1-3]. For WDM systems and in the presence of high bit rate per channel, the obstacle consequences of dispersion together with nonlinearity have to be managed to accomplish transmission through each valuable distance. Nonlinear effects are one of the most optical transmission system restrictions. When the total light power in a fiber is increased, the nonlinear effect becomes uncontrolled and may affect signal efficiency and degrade system performance [4]. One of the main factors that may cause interference in transmission systems, where there are channels are arranged to separate them from similar distances, is called the FWM. For optical communication systems, suppressing FWM efficiency is the main objective. A few methods were done to mitigate the defect of FWM efficiency and also modify the signal output [5-14].

Dispersion compensation techniques using fibers with opposite dispersion values are a crucial method in which the whole cumulative dispersal will be kept low. In these techniques, it employs SingleMode Fiber (SMF) with Dispersion Compensation Fiber (DCF), the largest negative value of dispersal of DCF enable us to neutralize the positive dispersal of SMF [15, 16]. In standard transmission distances, the RZ and NRZ modulation forms are in most cases employed. The experiments and surveys have offered 
that RZ takes into account to be top priority relative to the normal NRZ systems, as long as typical singlemode fibers are utilized as communication media $[17,18]$. Whereas, due to the narrower optical spectrum of the NRZ format, NRZ can achieve higher spectral efficiency in WDM systems in comparison to RZ in the linear pattern. Recently, methods of optical multiplexing and demultiplexing with the combination of delay lines are one of the considerable various FWM suppression methods [19], In addition, the use of polarization technique and the technique of space between the channels contributed to reduce interference with the signals transmitted to some extent [20-23]. For all techniques done, the level of FWM crosstalk on the main channels still not much suppressed and thus the system efficiency stays low and must be improved. The features of FWM are very connected with the modulation forms. Under high data rate effect, FWM crosstalk will change and depend on the immunity of modulation formats. This work presents the durability of NRZ, RZ, MDRZ and Gaussian modulation to the FWM nonlinear under high data rate of $200 \mathrm{~Gb} / \mathrm{s}$. The suggested system design was implemented with different transmission distances and input signal power around $12 \mathrm{dBm}$.

\section{MOSELING AND PROPOSED SYSTEM DESIGN}

Figure 1 clarifies the proposed system design. The transmitter and receiver are the two basic elements which the suggested system design is made up from. To produce the carrier signal at the transmitter component, the continual wave laser layout (L1-L4) is employed. The frequency of first channel is adjusted to $191.5 \mathrm{THz}$, and the interval between every channel and another is $100 \mathrm{GHz}$. Every channel is modulated with $50 \mathrm{~Gb} / \mathrm{s}$ Bit rate. The external modulator consists of NRZ, MDRZ, RZ and Gaussian transmitter circuits.

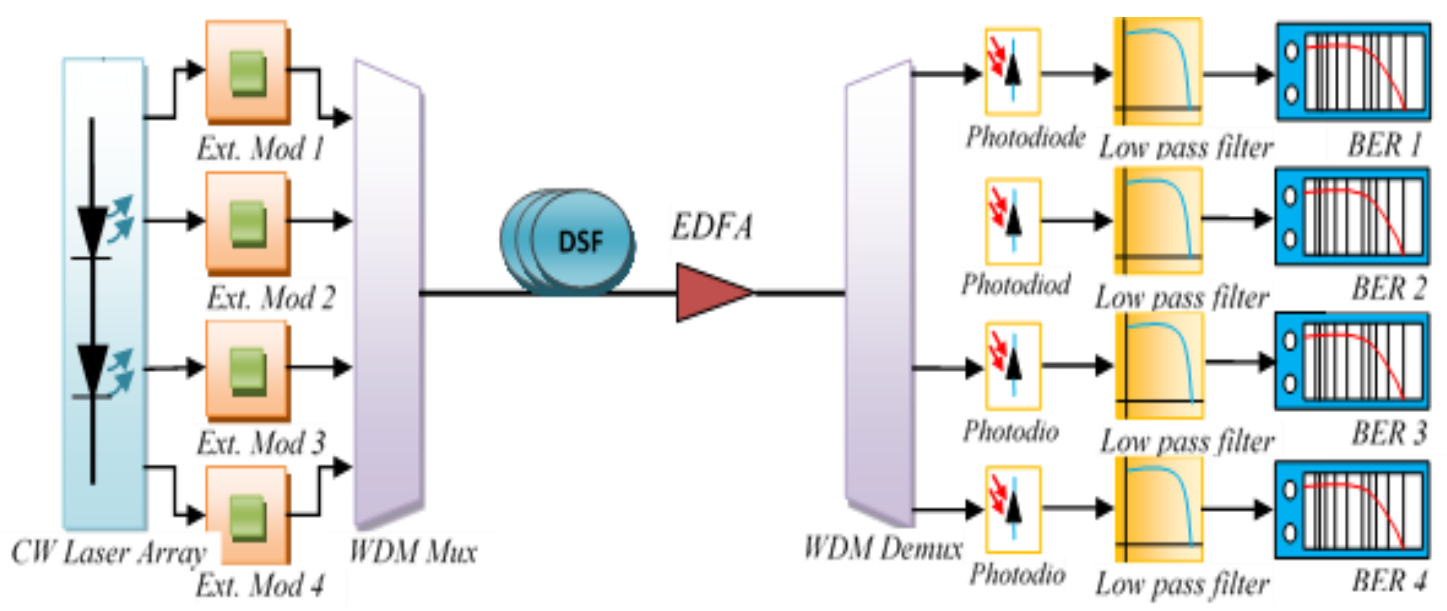

Figure 1. Proposed system design of of NRZ, MDRZ and RZ

The transmitter system configuration of every modulation utilized is illustrated in Figure 2. At the point, an intensity modulator called Mach Zehnder Modulator (MZM) is connected to the transmitter system. Seven spans that the optical link includes. Also, each span is consists of Dispersion Shifted Fiber and follow it by optical fiber amplifiers, which own noise figure, magnitude of $5 \mathrm{~dB}$ and gains of $20 \mathrm{~dB}$. When the signal communicates by the channel of the optical fiber, the signal will be detected and obtained at the receiver. An Avalanche Photo Diode (APD) is used to detect the signal to obtain a direct detection. From that point, it is transmitted by the low-pass Bessel filter. The BER analyzer is directly connected to the electrical filter is utilized to produce the diagram. Table 1 illustrates the system simulation parameters. 


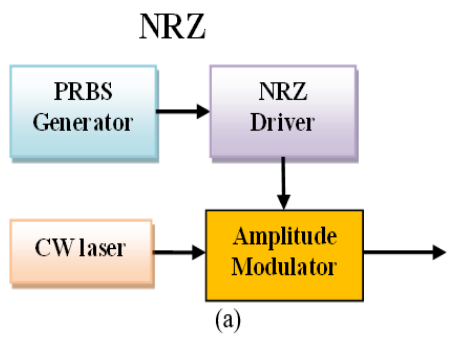

(a)

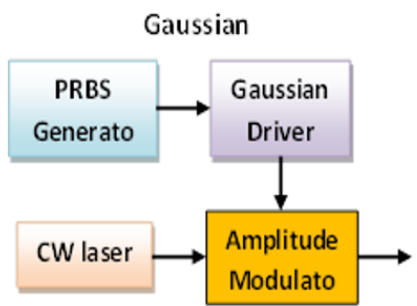

(c)
RZ

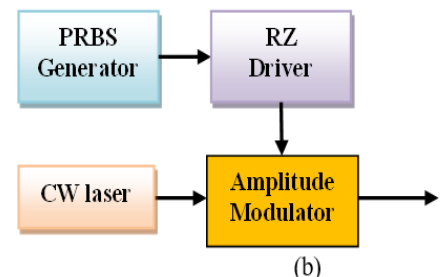

(b)

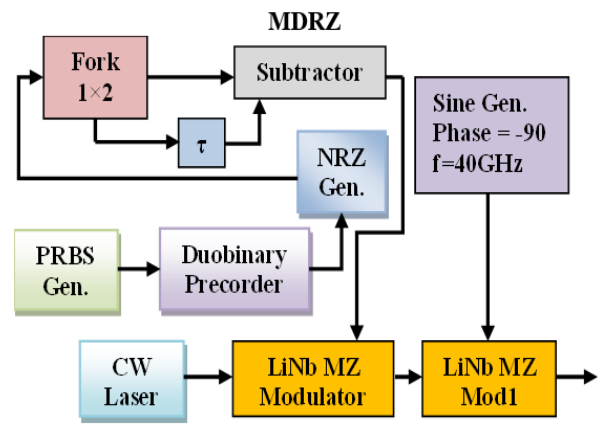

(d)

Figure 2. Proposed block diagram of optical transmitter for: (a) NRZ, (b) RZ, (c) Gaussian and (d) MDRZ

Table 1. Parameters specifications of optical transmission system

\begin{tabular}{lll}
\hline Parameter & Unit & Values \\
\hline Input power, $\mathrm{P}_{\mathrm{i}}$ & $\mathrm{dBm}$ & 12 \\
Number of channel, $\mathrm{N}_{\mathrm{c}}$ & -- & 4 \\
Total data rate, $\mathrm{B}$ & $\mathrm{Gb} / \mathrm{s}$ & 200 \\
Input frequencies, $\mathrm{F}_{\mathrm{in}}$ & $(\mathrm{THz})$ & $191.5-191.8$ \\
Channel Spacing, $\Delta \mathrm{f}$ & $(\mathrm{GHz})$ & 100 \\
Fiber Parameters & & \\
Fiber type & $\mathrm{DSF}$ G.653 & \\
Length of fiber, $\mathrm{L}$ & $\mathrm{Km}$ & 100 to 700 \\
Fiber dispersion, $\mathrm{D}_{\mathrm{c}}$ & $\mathrm{ps} / \mathrm{nm}^{\mathrm{km}}$ & 0.3 \\
Dispersion slope & $\mathrm{ps} / \mathrm{nm}^{2} \cdot \mathrm{km}$ & 0.075 \\
Cross effective area, $\mathrm{A}_{\text {eff }}$ & $\mu \mathrm{m}^{2}$ & 50 \\
Degeneracy factor, $\mathrm{D}$ & --- & 6 \\
Third order Susceptibility, $\mathrm{X} 111$ & $\mathrm{~m} 3 / \mathrm{w} . \mathrm{s}$ & $6 \times 10^{-15}$ \\
Refractive index & $\mathrm{n}$ & 1.48 \\
\hline
\end{tabular}

The thermal along with shot noises are occurring, the probability distribution functions will be Gaussian act. The significant issue which is seen that the FWM commotions have likelihood circulation probability isn't Gaussian. This issue is causing disturbance on both thermal with shot noises [24]. Optical amplifier noise is deemed as well. The interference between amplified spontaneous emission (ASE) noise and FWM noise is ignored [25]. In the Gaussian estimation the error probability is written as [24]:

$$
\mathrm{P}_{\mathrm{e}}=\frac{1}{\sqrt{2 \pi}} \int_{\mathrm{Q}}^{\infty} \exp \left(-\frac{\mathrm{t}^{2}}{2}\right) \mathrm{dt}
$$

with

$$
Q=\frac{K P_{S}}{\sqrt{N_{t h}+N_{S h}+N_{a m p}+2 K^{2} P_{S}^{2} C_{I M}^{(m)}}+\sqrt{N_{t h}}} .
$$

where:

$$
\begin{aligned}
& K=\frac{\eta_{d} e}{h f} . \\
& P_{s}=G L_{t} P_{1} .
\end{aligned}
$$




$$
\begin{aligned}
& N_{t h}=\frac{Q_{0}^{2}}{4}\left(\frac{K P_{s 0}}{Q_{0}^{2}}-\mathfrak{R}\right)^{2} . \\
& N_{s h}=\mathfrak{R} K P_{s} . \\
& N_{a m p}=k_{a} K^{2}(G-1)(m+1) L_{t} P_{s} . \\
& k_{a}=4 n_{s p} h f B_{f} . \\
& C_{I M}^{(m)}=\frac{1}{8} \sum_{p \neq q \neq r \neq s} \frac{P_{p q r}}{P_{s}}+\frac{1}{4} \sum_{p \neq q \neq r=s} \frac{P_{p q s}}{P_{S}}+\frac{1}{4} \sum_{p=q \neq r} \frac{P_{p p r}}{P_{s}} .
\end{aligned}
$$

Here, $C_{I M}^{(m)}$ is the crosstalk components of the FWM, $P_{s}$ is the signal light peak power received, $N_{t h}$ is the power of thermal noise, $N_{s h}$ is the power for shot noise, $N_{a m p}$ is the noise power for optical amplifier. $\eta_{d}$ is the detector quantum efficiency, $e$ is the electric charge, $h$ is Planck's constant, and $f$ is the light frequency. $G$ is the gain of optical pre-amplifier, $\mathrm{m}$ is the nodes number, $L_{t}$ is the optical pre-amplifier coupling loss, and $P_{1}$ is the input power into the pre-amplifier in channels one. In this work, $Q_{0}$ is a $Q$ value corresponding to a required $B E R, P_{s o}$ is the signal light peak power received for a required BER with neither FWM nor ASE, and $\Re=2 e B_{f} M x$ where $B_{f}$ is the bandwidth of electrical filter, $M$ is the factor of APD current multiplication, and $x$ is the excess noise factor of APD. Where the receiver parameters are $B_{f}=10 \mathrm{GHz} ; M=15$, and $x=0.7$ [24]. Where supposed that a quantum efficiency $\eta_{d}$ of $85 \%$ is taken for an APD into consideration [26]. In random RZ, the bandwidth will be double compared to NRZ and both $P_{p q r}$ and $P_{p q s}$ will multiply by probability $(0.25)$, and $P_{p p r}$ multiply by probability $(0.5)$, where the total probability of all FWM components equal to (1).

$$
\begin{aligned}
& \mathrm{C}_{\mathrm{IM}}^{(\mathrm{m})} \text { is replaced byC } \mathrm{RRZ}_{\mathrm{RRZ}}^{(\mathrm{m})} \text { as follows: } \\
& \mathrm{C}_{\mathrm{RRZ}}^{(\mathrm{m})}=\frac{1}{4} \cdot \frac{1}{8} \sum_{\mathrm{p} \neq \mathrm{q} \neq \mathrm{r} \neq \mathrm{s}} \frac{\mathrm{P}_{\mathrm{pqr}}}{\mathrm{P}_{\mathrm{s}}}+\frac{1}{4} \cdot \frac{1}{4} \sum_{\mathrm{p} \neq \mathrm{q} \neq \mathrm{r} \neq \mathrm{s}} \frac{\mathrm{P}_{\mathrm{pqs}}}{\mathrm{P}_{\mathrm{S}}}+\frac{1}{2} \cdot \frac{1}{4} \sum_{\mathrm{p} \neq \mathrm{q} \neq \mathrm{r}} \frac{\mathrm{P}_{\mathrm{ppr}}}{\mathrm{P}_{\mathrm{s}}} .
\end{aligned}
$$

In terms of NRZ modulation the FWM crosstalk will become as:

$$
\begin{aligned}
& \mathrm{C}_{\mathrm{NRZ}}^{(\mathrm{m})}=\frac{1}{8} \sum_{\mathrm{p} \neq \mathrm{q} \neq \mathrm{r} \neq \mathrm{s}} \frac{\mathrm{P}_{\mathrm{pqr}}}{\mathrm{P}_{\mathrm{S}}}+\frac{1}{4} \sum_{\mathrm{p} \neq \mathrm{q} \neq \mathrm{r} \neq \mathrm{s}} \frac{\mathrm{P}_{\mathrm{pqs}}}{\mathrm{P}_{\mathrm{s}}}+\frac{1}{4} \sum_{\mathrm{p} \neq \mathrm{q} \neq \mathrm{r}} \frac{\mathrm{P}_{\mathrm{ppr}}}{\mathrm{P}_{\mathrm{S}}} . \\
& \mathrm{P}_{\mathrm{S}}=-\frac{\mathrm{Kk} \mathrm{a}(\mathrm{G}-1) \mathrm{L}_{\mathrm{t}}(\mathrm{m}+1)+\Re}{\mathrm{K}\left(4 \mathrm{C}_{\mathrm{IM}}^{(\mathrm{m})}-1 / 2 \mathrm{Q}^{2}\right)}+\frac{\sqrt{\left[\mathrm{Kk}_{\mathrm{a}}(\mathrm{G}-1) \mathrm{L}_{\mathrm{t}}(\mathrm{m}+1)+\Re\right]^{2}-\mathrm{N}_{\mathrm{th}} \mathrm{K}\left(8 \mathrm{C}_{\mathrm{IM}}^{(\mathrm{m})}-1 / \mathrm{Q}^{2}\right)}}{\mathrm{K}\left(4 \mathrm{C}_{\mathrm{IM}}^{(\mathrm{m})}-1 / 2 \mathrm{Q}^{2}\right)} . \\
& \mathrm{Q}=\frac{\mathrm{KP}_{\mathrm{S}}}{2 \sqrt{\mathrm{N}_{\mathrm{th}}+\mathrm{N}_{\mathrm{Sh}}+\mathrm{N}_{\mathrm{amp}}+2 \mathrm{~K}^{2} \mathrm{P}_{\mathrm{S}}^{2} \mathrm{C}_{\mathrm{IM}}^{(\mathrm{m})}}} .
\end{aligned}
$$

\section{RESULT ANALYSIS AND DISCUSSIONS}

In this section, the fiber length effect on FWM power with four modulation, pulse types which are NRZ, MDRZ, RZ and Gaussian was evaluated. The system performance is simulated in terms of BER among modulation formats mention.

\subsection{Averaged FWM crosstalk}

System simulation was performed by increasing the fiber length values from 100 to $700 \mathrm{~km}$, i.e., seven spans; with available simulations for all modulations. Figure 3 explains the FWM versus transmission distance variation under 200Gbls. An increase in the transmission distance can increase the FWM crosstalk on the channel and thus decrease the optical system efficiency. At low values of transmission distance, the nonlinear effect has a little effect on system performance i.e. FWM was low. When the power of the channel increase the crosstalk will appear stronger and impairment the transmission system because it causes depletion of the channel power. 


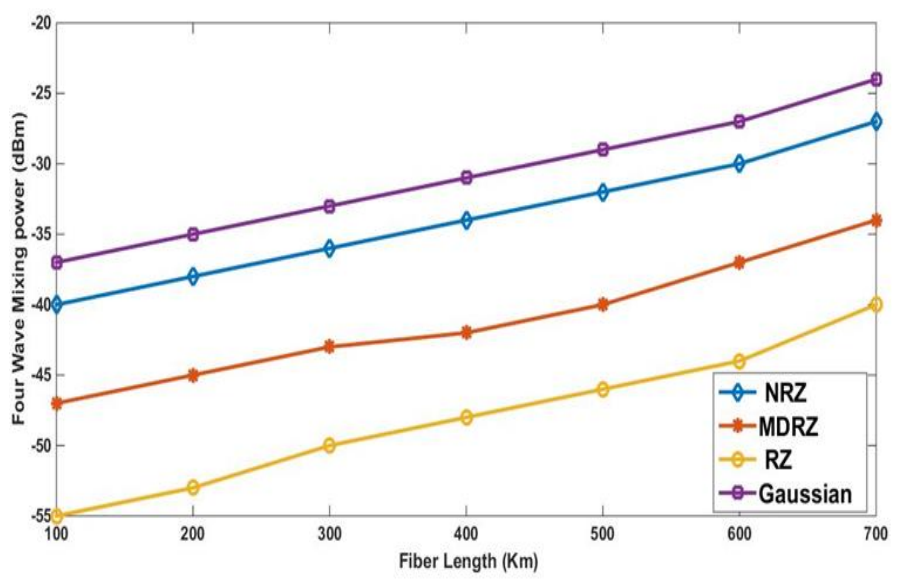

Figure 3. FWM power versus fiber length variation for different modulation

Figure 4(a-d) shows the optical spectrum of $700 \mathrm{~km}$ optical fiber. It is obvious from this figure that the FWM power was high and reaches to $-24 \mathrm{~dB}$ in Gaussian modulation format, while the availability of both MDRZ and RZ modulation, the FWM powers were dropped to -34 and $-40 \mathrm{dBm}$ respectively. This means that RZ modulation appears better to tolerate to FWM crosstalk compared to its competitors.

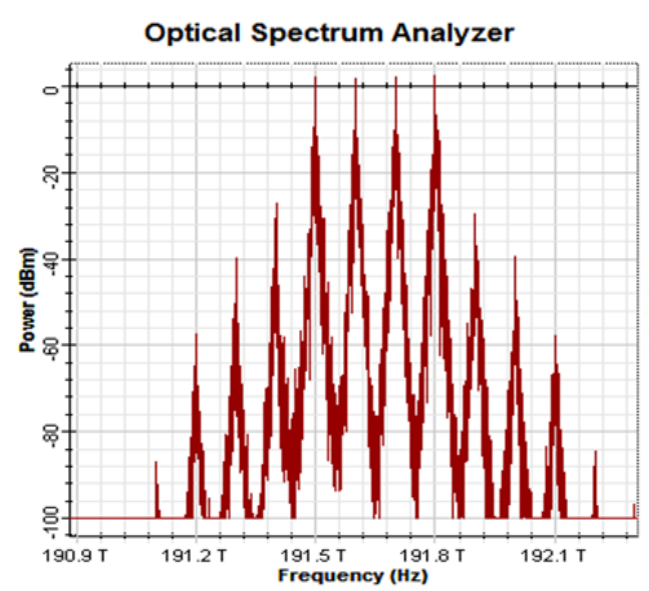

(a)

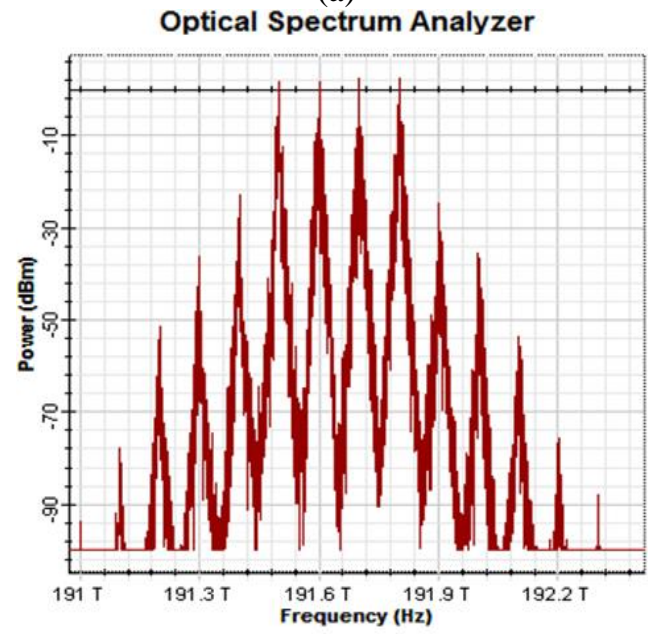

(c)

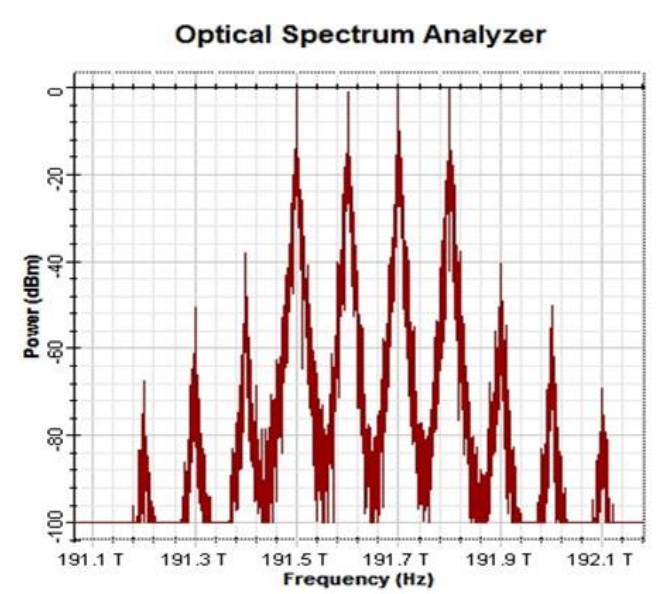

(b)



(d)

Figure 4. Optical spectrum analyzer after $700 \mathrm{~km}$ distance with modulation format types: (a) NRZ, (b) RZ, (c) Gaussian and (d) MDRZ 


\subsection{Bit error rate and eye diagram}

Figure 5 explains the relation between the fiber lengths versus BER under data rate influence of 200 Gbls. The system performance has been performed by using single mode fiber (SMF) and for three modulation types used. It can be seen that as an increment in the transmission distance lead to increase the bit error rate in the system. The trend of the system performance was similar to all channels used i.e the RZ reveals better system performance. It is observed from Figure 5(a), in the first channel, the RZ modulation technique offered a minimum BER of $1.3 \times 10^{-13}$ at transmission distance of $700 \mathrm{~km}$. However, with NRZ, MDRZ and Gaussian modulation, pulse, the BERs were $1.3 \times 10^{-4}, 1.3 \times 10^{-6}$ and $1.3 \times 10^{-2}$ respectively at the same channel and fiber length.



(a)

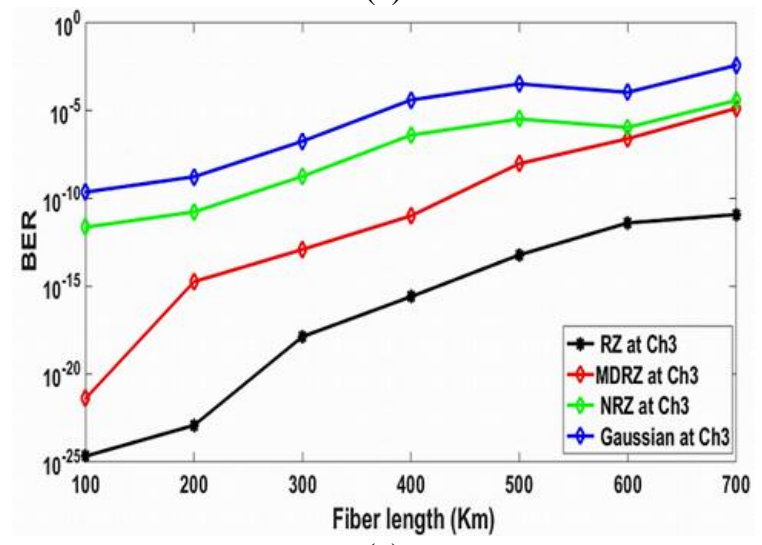

(c)

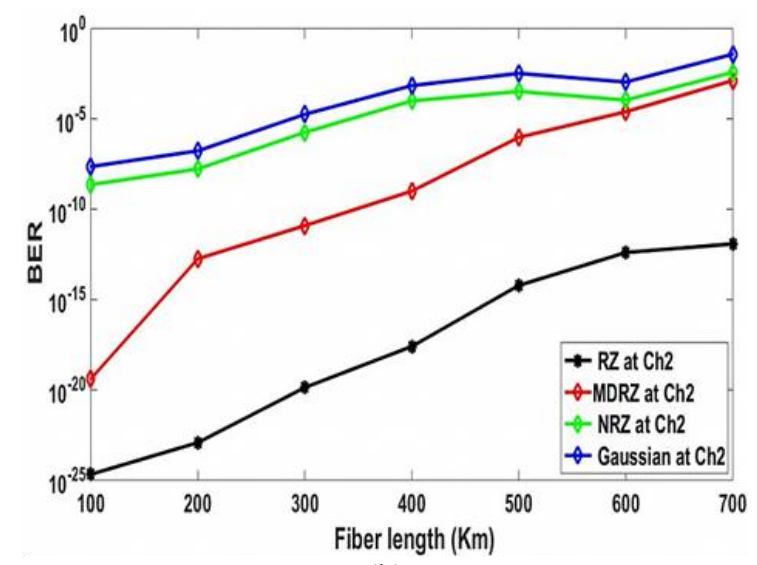

(b)

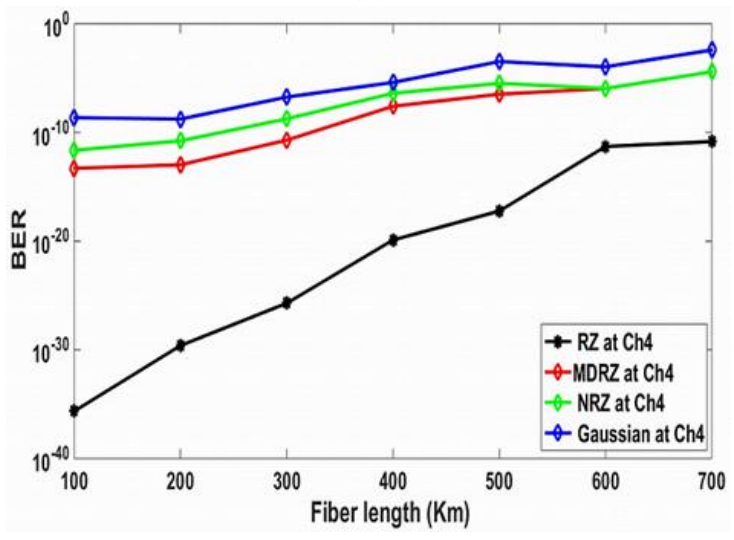

(d)

Figure 5. BER versus fiber length for modulation technique of (a) Ch1, (b) Ch2, (c) Ch3 and (d) Ch4

More importantly, it can be concluded from the modulation behavior with high values of both data rate and distance, that RZ modulation reveals more adequacy to nonlinear effect than NRZ and MDRZ. Figure 6 shows that the optimum eye diagram for all modulation used after $700 \mathrm{~km}$ and measured at the first channel. The optimum eye diagram was the height with RZ modulation of BER $\left(1.2 \times 10^{-13}\right)$. Inversely with NRZ and Gaussian modulation, where the eye diagram was less clarity and high of BERs $\left(1.3 \times 10^{-4}\right)$ and $\left(1.3 \times 10^{-2}\right)$ consequently on same channel. More opening eyes diagram means that the RZ modulation has high firmness to nonlinear effect in high data rate, also improving in the succeeding rate of receiving bits ( 1 and 0$)$ detection with little defect or no noise due to the overlapping. 


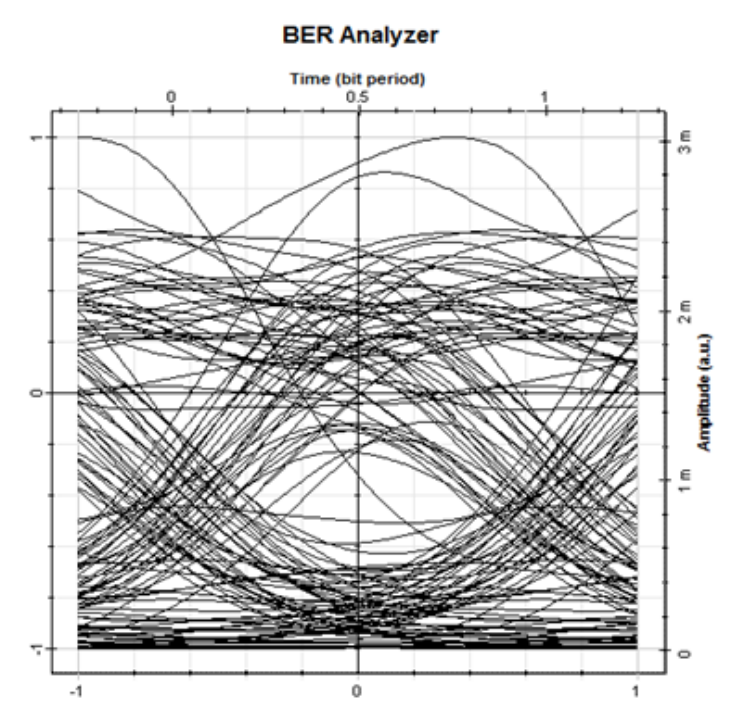

(a)

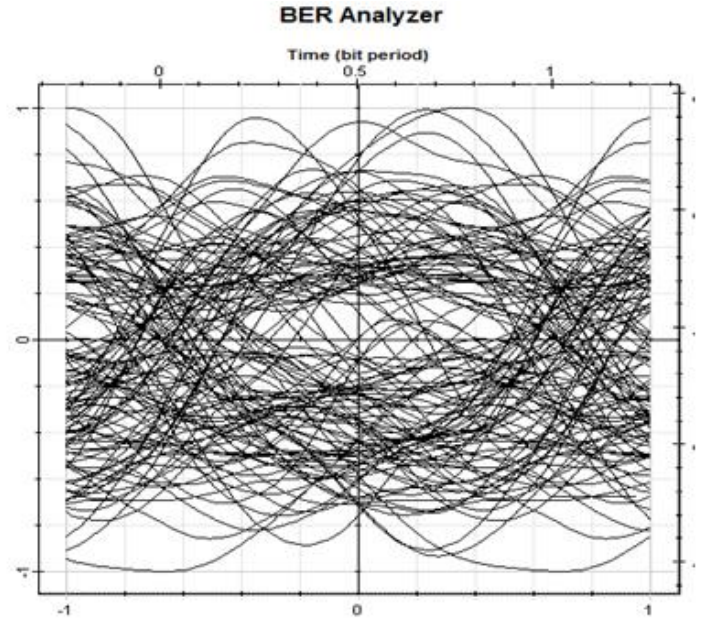

(c)

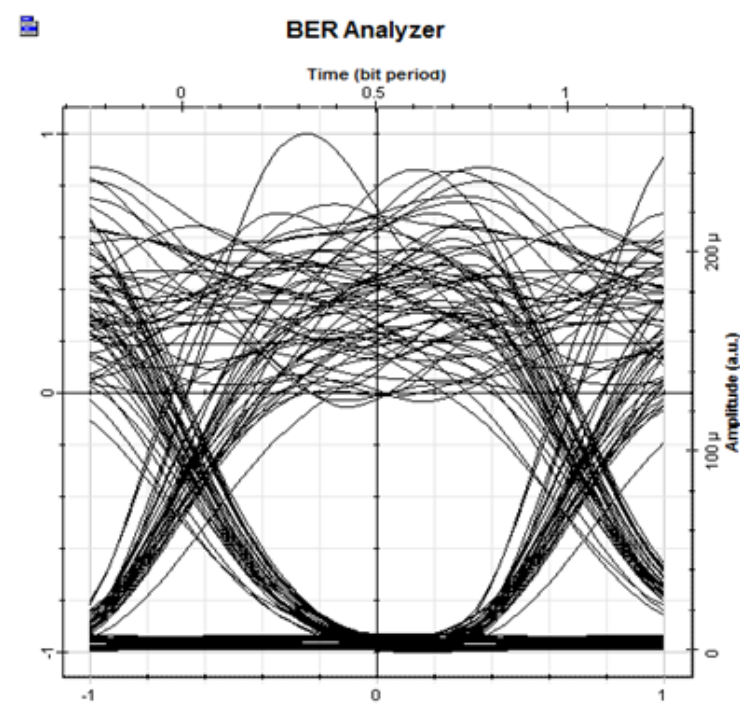

(b)

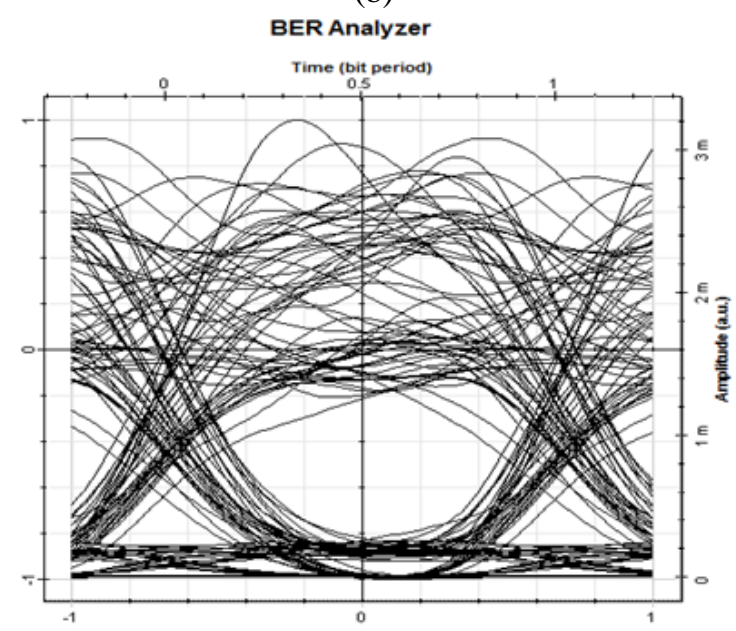

(d)

Figure 6. Eye diagram of modulation technique using (Ch1): (a) NRZ modulation, (b) RZ modulation,

(c) Gaussian modulation and (d) MDRZ modulation

\section{CONCLUSION}

This work provides a complete analysis of optical transmission performance under the influence of fiber length tuning and the use of high data rate with NRZ, RZ, MDRZ and Gaussian. Experimental results show that FWM power is suppressed by more than $14 \mathrm{~dB}$ through the proposed RZ modulation procedure. For BER in the first channel, RZ offers the lowest BER rate of $\left(1.2 \times 10^{-13}\right)$ at a distance of $700 \mathrm{~km}$ of fiber compared to the other configurations used. Finally, we can conclude that the RZ adjustment provides more robustness for crosstalk routing even with high value data rate.

\section{REFERENCES}

[1] M. H. C. Hansen, et al., "Demonstration of 5.1 Tbit/s Data Capacity on a Single Wavelength Channel," Opt Express, vol. 18, pp. 1438-1443.

[2] M. H. C. Hansen, et al., "1.28 TBIT/s single-Polarisation serial OOK Optical Data Generation and Demultiplexing," Electron Lett, vol. 45, pp. 280-281, 2009.

[3] S. N. Shahiand and Kumar S., 'Reduction of Nonlinear Impairments in Fiber Transmission System Using Fiber and/or Transmitter Diversity," Opt. Commune., vol. 285, pp. 3553-3558, 2012.

[4] T. Shimizu, et al., "Evaluation Methods and Requirements for The Stimulated Brillion Scattering Threshold in a Single-Mode Fiber," Optic. Fiber Technology, vol. 14, pp. 10-15, 2008.

[5] H. J. Abed, et al., "Recent four-Wave Mixing Suppression Methods," Optik, vol. 124, pp. 2214-2218, 2013. 
[6] H. J. Abd, et al., "Priority-Based Parameter Optimization Strategy for Reducing the Effects of Four-Wave Mixing on WDM System," Optik, vol. 125, pp. 25, 2014.

[7] H. Abd, et al., "Four-wave Mixing Crosstalk Suppression Based on the Pairing Combinations of Differently Linear-Polarized Optical Signals," Sci. World J., vol. 2014, pp. 1, 2014.

[8] H. J. Abd, et al., "Four-wave Mixing Reduction Technique Based on Smart Filter Approach," International Journal of Electronics, vol. 102, pp. 1056-1070, 2015.

[9] H. J. Abed, et al., "Comparison Among Different Types of Advanced Modulation Formats Under Four Wave Mixing Effects," Ukrainian Journal of Physics, pp. 326-334, 2013.

[10] H. J. Abd and M. S. Almahanna, "Suppression of Nonlinear Effect for High Data Transmission Rate with a WDM Using the Optimization Properties," Ukrainian Journal of Physics, vol. 62, pp. 583-588, 2017.

[11] N. Salim, et al., "Four-Wave Mixing Suppression Method Based on Odd-Even Channels Arrangement Strategy," Progress In Electromagnetics Research, vol. 66, pp. 163-172, 2018.

[12] H. J. Abd, et al., "Mitigation of FWM crosstalk in WDM system Using Polarization Interleaving Technique Photonics (ICP)," 2013 IEEE 4th International Conference on, pp. 117-119, 2013.

[13] H. J. Abed, et al., “A new FWM Reduction Technique Based on Damping Selective Wavelengths,” pp. 957-962.

[14] A. H. Jabber, et al., "Influence of four wave mixing on modulation format performance under $100 \mathrm{~Gb} / \mathrm{s}$ data rate Research and Development (SCOReD)," 2012 IEEE Student Conference on, pp. 129-133, 2012.

[15] G. P. Agrawal, "Nonlinear Fiber Optics," Academic Press, New York, 2001.

[16] G. P. Agrawal, “Applications of Nonlinear Fiber Optics,” Academic Press, New York, 2001.

[17] M. I. Hayee and A. E. Willner, "NRZ Versus RZ in 10-40-Gb/s Dispersion Managed WDM Transmission Systems," IEEE Photonics Technol. Lett., vol. 11, pp. 991-993, 1999.

[18] G. Bosco, et al., "On the use of NRZ, RZ, and CSRZ Modulation at $40 \mathrm{~Gb} / \mathrm{s}$ with narrow DWDM channel spacing," J. Lightwave Technol., vol. 20, pp. 1694, 2002

[19] A. Hodzik, et al., "Alternative Modulation Formats in $\mathrm{N} \_40 \mathrm{~Gb} / \mathrm{s}$ WDM Standard Fiber RZ-Transmission Systems," IEEE J. LightwaveTechnol., vol. 20, pp. 598, 2002.

[20] D. Dahan and G. Eisenstein, "Numerical Comparison Between Distributed and Discrete Amplification In a Pointto-Point 40-Gb/s 40-WDM-Based Transmission System with Three Different Modulation Formats," J. Lightwave Technol., vol. 20, pp. 379, 2002.

[21] R. S. Kaler, et al., "Simulation Results for DWDM Systems with Ultra-High Capacity," Int. J. Fiber Integrated Opt., vol. 21, 2002.

[22] P. J. Winzer and R. J. Essiambre, "Advanced Optical Modulation Formats," Proceedings of the IEEE, vol. 94, pp. 952-985, 2006.

[23] S. Singh and R. S. Kaler, "Simulation of DWDM Signals Using Optimum Span Scheme with Cascaded Optimized Semicon-Ductor Optical Amplifiers," Optik—Int. J. Light Electron. Opt., vol. 118, pp. 74-82, 2007.

[24] K. Inoue, et al., "Crosstalk and Power Penalty Due to Fiber Four-Wave Mixing in Multichannel Transmissions," J. Lightwave Technol., vol. 12, pp. 1423, 1994.

[25] S. P. Singh, et al., "Performance of All-Optical WDM Network in Presence of Four-Wave Mixing, Optical Amplifier Noise, and Wavelength Converter Noise," Fiber and Integrated Optics, vol. 26, pp. 79-97, 2007.

[26] K. Ema, et al., "All Optical Sub Tbits/s Serial to Parallel Conversion Using Excition in Giant Nonlinearity," Appl. Phys. Lett., vol. 59, pp. 2799, 1991.

\section{BIOGRAPHIES OF AUTHORS}

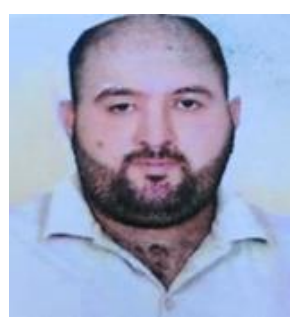

Ali Shaban Hassooni, MSc. Electrical Engineering was born in Babylon on July 7, 1981. He obtained his BSc degree (2003) in Electrical Engineering at the Faculty of Engineering, University of Babylon and MSc degree (2011), in electronic and communication engineering at the Department of Electrical Engineering, University of Babylon, Currently he works at the Biomedical Department at the Faculty of Engineering, University of Babylon. His main interest is medical signal processing, Microcontroller systems, Biomedical sensors and control system analysis.

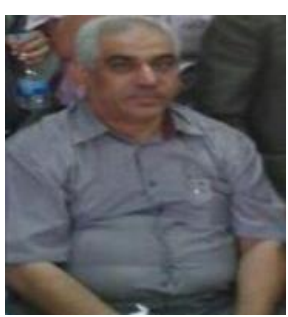

Mr. Murad Obaid Abed earned his MSc. in the field of Electrical Engineering from university of technology, Iraq, 2002. He has more than five years of experience in teaching. He completed his BSc in Electrical Engineering, University of Technology, Baghdad, Iraq, 1983. His research interests include communication, wavelet transform, electronic system design and Quantum communication. 


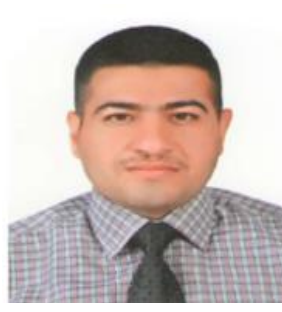

Ehab AbdulRazzaq Hussein, PhD. \& MSc. Electrical Engineering was born in Babylon on January 1, 1976. He obtained his BSc degree (1997) in Electrical Engineering at the Faculty of Engineering, University of Babylon and MSc degree (2000), in electrical engineering at the Department of Electrical Engineering, University of Technology and his PhD. Degree from the Department of Electrical Engineering at the Faculty of Engineering, University of Basrah, Currently he works as assistant professor at the Electrical Department at the Faculty of Engineering, University of Babylon. His main interest is signal processing, analysis, information transition, sensors and control system analysis.

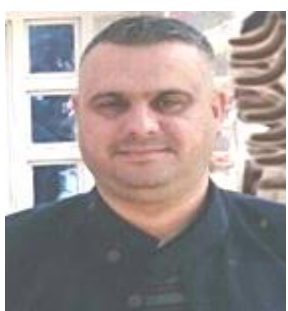

Associate professor Dr. Haider J. Abd earned his Ph.D. in the field of Electrical Engineering from university of Tenaga Nasional, Malaysia, 2014. He has more than ten years of experience in teaching. He completed his MSc, in Electrical Engineering, university of Baghdad, Baghdad, Iraq, 2005. His research interests include Optical fiber communication, Wireless communication, Digital signal processing, smart systems, Biomedical Engineering, Maglev system and Adaptive control system. 